See discussions, stats, and author profiles for this publication at: https://www.researchgate.net/publication/328329004

\title{
Structural Deformation and its Impact to Sandstone Reservoirs in Eastern
} Azerbaijan

Conference Paper · June 2018

DOI: 10.3997/2214-4609.201801590

\section{CITATIONS}

0

2 authors:

Gasham A Zeynalov

Khazar University

11 PUBLICATIONS 20 CITATIONS

SEE PROFILE
READS

32

Shahriyar Alkhasli

Khazar University

4 PUBLICATIONS OCITATIONS

SEE PROFILE 


\section{Th P4 16}

\section{Structural Deformation and its Impact to Sandstone Reservoirs in Eastern Azerbaijan}

G. Zeynalov* (Khazar University and Azerbaijan State Oil and Industry University), S. Alkhasli (Khazar University)

\section{Summary}

Azerbaijan territory is located in the Alpine-Himalayan fold belt and its main geo-structural elements are the South Caspian basin (SCB) in the east and the Kura basin in the west. This region structurally was complicated by northeast compressional deformation which caused generation of deformation bands in sandstones of plunging anticlines with significant influence to their reservoir properties. Among the folds of the Productive Series complicated with structural deformations, Maliy Kharami and Yasamal Valley fields in are of particular interest. The aim of this study is to evaluate the structurally deformed reservoir rock properties in mentioned fields based on outcrop measurements and lab experiments. The scope of the research includes examination of correlation between dipping of layers and quantity of deformation bands observed along and across steeply dipping and plunged layers of anticline limbs. Also, evaluation elastic properties prediction with respect to mineralogical composition, which controls elastic properties of the rock, its mineralogical composition has also been investigated. Influence of deformation bands on rock filtration properties is quantified on the field and lab-plug scales. A descending trend is observed between permeability of sandstones and number of deformation bands across the investigated anticline and compared to shale volume impact. 


\section{Introduction}

Structural deformation in sandstone reservoirs significantly influence to the accumulation and preservation of oil and gas. Impact of deformation bands to sandstone reservoirs can be considered as a function of their kinematics and petrophysical properties. Several investigations were performed for siliciclastic reservoirs by Tang \& Cui (2012), Zuluaga \& Rotevatn (2012) and Rotevatn et al. (2013) to analyze influence of deformation bands on reservoir rocks with respect to their permeability contrast with the host rock.

The aim of this study is to evaluate the reservoir rock properties in structurally deformed areas of the fields in Eastern Azerbaijan based on outcrop measurements and laboratory experiments. In order to study that how the structural deformation impact to the hydrocarbon accumulation, we did some field work and collected some core samples for analysis of deformation types in steeply dipping sandstone layers of the Productive Series which is considered the main oil and gas reservoir in the region.

The scope of the research includes examination of correlation between dipping of layers and quantity of deformation bands observed along and across steeply dipping and plunged layers of anticline limbs. Also, evaluation elastic properties prediction with respect to mineralogical composition, which controls elastic properties of the rock, its mineralogical composition has also been investigated. This was accomplished referring to shale volume of sandstones derived from field and XRD measurements. Influence of deformation bands on rock filtration properties is quantified on the field and lab-plug scales. A descending trend is observed between permeability of sandstones and number of deformation bands across the investigated anticline and compared to shale volume impact.

\section{Peculiarities of structural deformation in the Productive Series sandstone in East Azerbaijan}

Azerbaijan territory is located in the Alpine-Himalayan fold belt and its main geo-structural elements are the South Caspian basin (SCB) in the eastern and the Kura basin in the western parts (Fig.1). Eastern part of the Kura basin (Lower Kura basin) and Absheron Peninsula (in north-west of SCB) in Eastern Azerbaijan are characterized by high sedimentation rates in recent Pliocene-Quaternary time.

The Productive Series (Lower Pliocene), considered the main reservoir rock in the South Caspian and nearby Kura basins, was accumulated by the Paleo-Volga, and Paleo-Kura rivers (Jones and Simmons, 1996; Reynolds et al., 1998). Among the folds of the Productive Series complicated with structural deformations, Maliy Kharami in the Lower Kura basin and Yasamal Valley in the Absheron Peninsula are of particular interest.

Maliy Kharami is located in the homonymous mountain ridge with steep and very complicated slopes. According to Alizadeh et al. (1966), this brachyanticlinal fold system has an asymmetrical shape, with gentle $\left(45-55^{\circ}\right) \mathrm{NE}$ and steep $\left(80^{\circ}\right)$ to overturned SW limbs (Fig. 2). Two relatively parallel faults stretch along the axis of the anticline, forming a latitudinal crumpled zone. The faults have raised and slightly overturned the NE limb of the fold towards the SW. This crumpled zone is associated with a mud volcano located at the axis of the south-eastern pericline of the structure. Hydrocarbon seeps are observed across entire territory of the crumpled zone and mud volcano, and also in exposed oilsaturated sandstone layers of the Productive series. Deformation bands have been poorly observed in the outcrops of the Productive Series in the Maliy Kharamy anticline due to their limited exposure in discontinuous areas of the field.

However, the south-southeast plunging Yasamal anticline, where the Productive Series (Balakhany Suite) are widely exposed, has better conditions for studying deformation bands. The Yasamal anticline was formed as a result of folding during the late Pliocene (Gurevich and Chilingar, 1995). The structure is complicated by three longitudinal faults at its crest - one of which is a thrust fault (Alizadeh et al., 1966, Allen et al., 2003), possibly caused by overturning of the east limb of the anticline - and by a series of latitudinal normal and reverse faults. The structure is asymmetric, with 


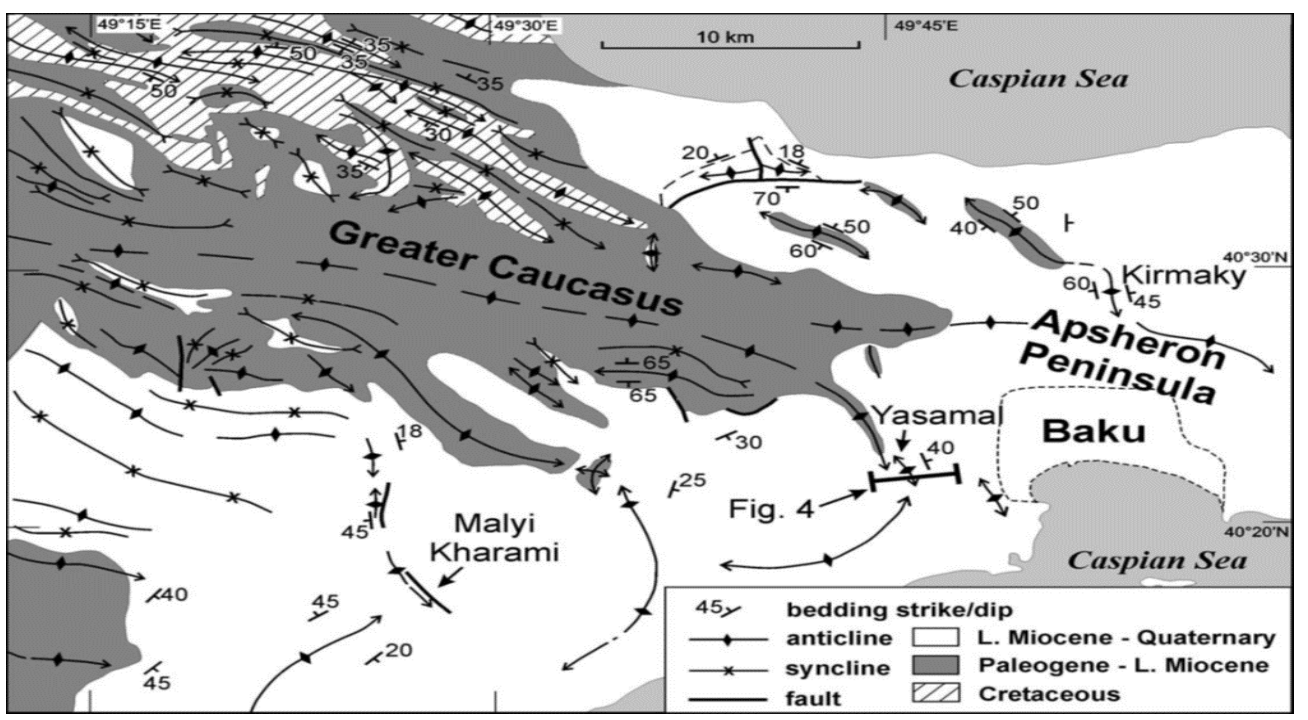

Figure 1. Simplified geological map of the Eastern Azerbaijan (modified by Allen et al., 2003)

the west limb dipping at around 40 degrees, and the east limb dipping at near-vertical position. The overturned layers of the east limb can be observed along the entire flank. The layers at the east limb with certain numbers of deformation bands are slightly declined from vertical position and are dipping towards the West.
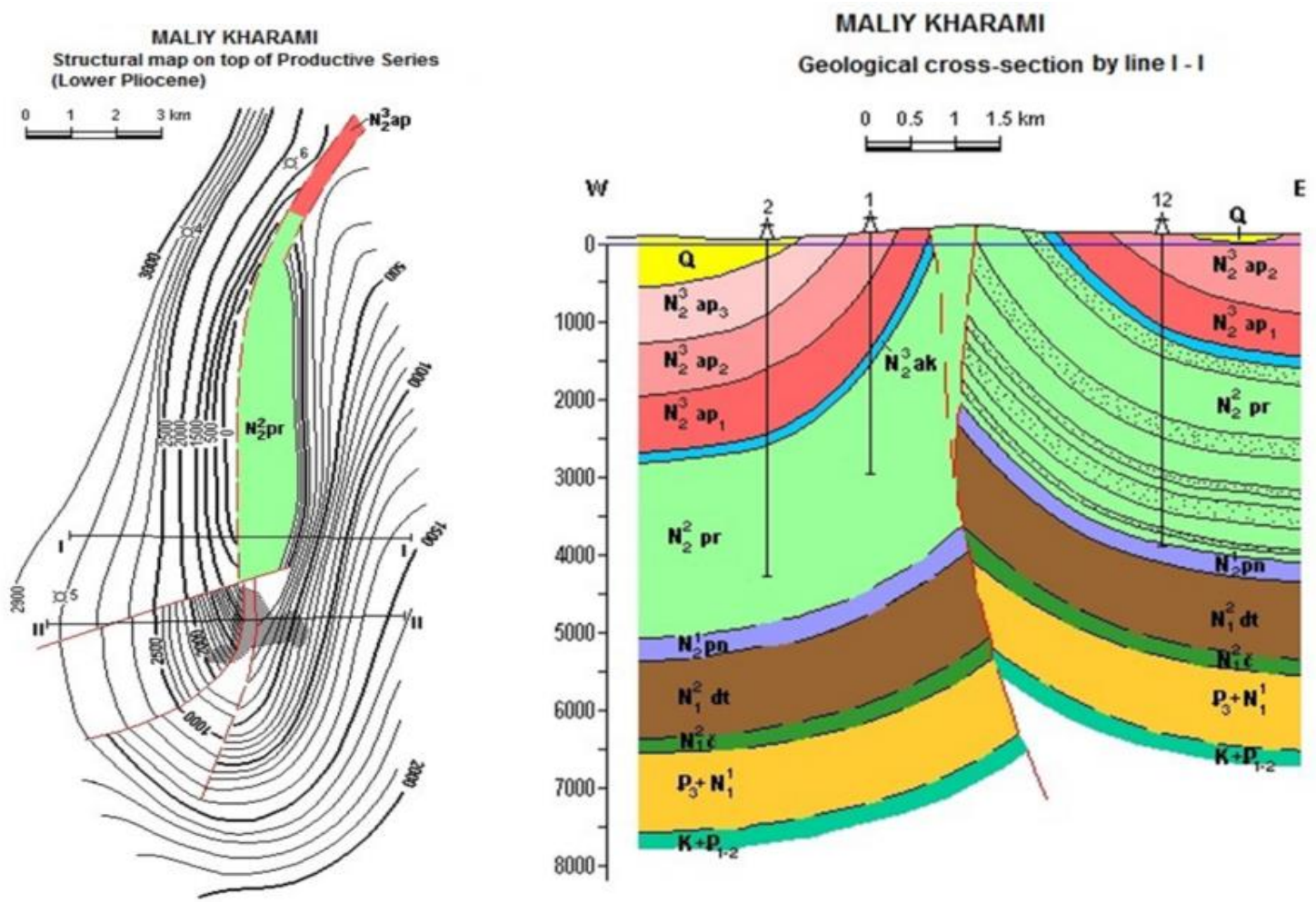

Figure 2: a) Structural map on top of the Productive Series; b)Geological cross-section of Maliy Kharami field

\section{Impact of deformation bands to reservoir properties of the sandstones}

Population of deformation bands on the field scale may exhibit a local character. Structure of Yasamal anticline suggests that the east limb is under relatively greater stress, as can be inferred from the steeply dipping and overturned layers. Thus, it is fair to expect a decent number of deformation bands 
on the outcrops of this flank. One of the major reasons that deformation bands form in highly porous clean sandstones is lack of ductility. This feature alters with the presence of ductile minerals. Particularly, clays tend to adsorb radioactive elements causing higher gamma ray emission in sandstones. Portable tool (MGS-150) was used to measure the natural radioactivity of Balakhany Suite in order to construct a comprehensive GR log with $30 \mathrm{~cm}$ interval. All of the field measurements were performed in three locations: the south pericline $(\log 1)$, and the southern $(\log 2)$ and northern (Log 3) parts of the east limb (Fig.3), where a certain number of deformation bands were observed.

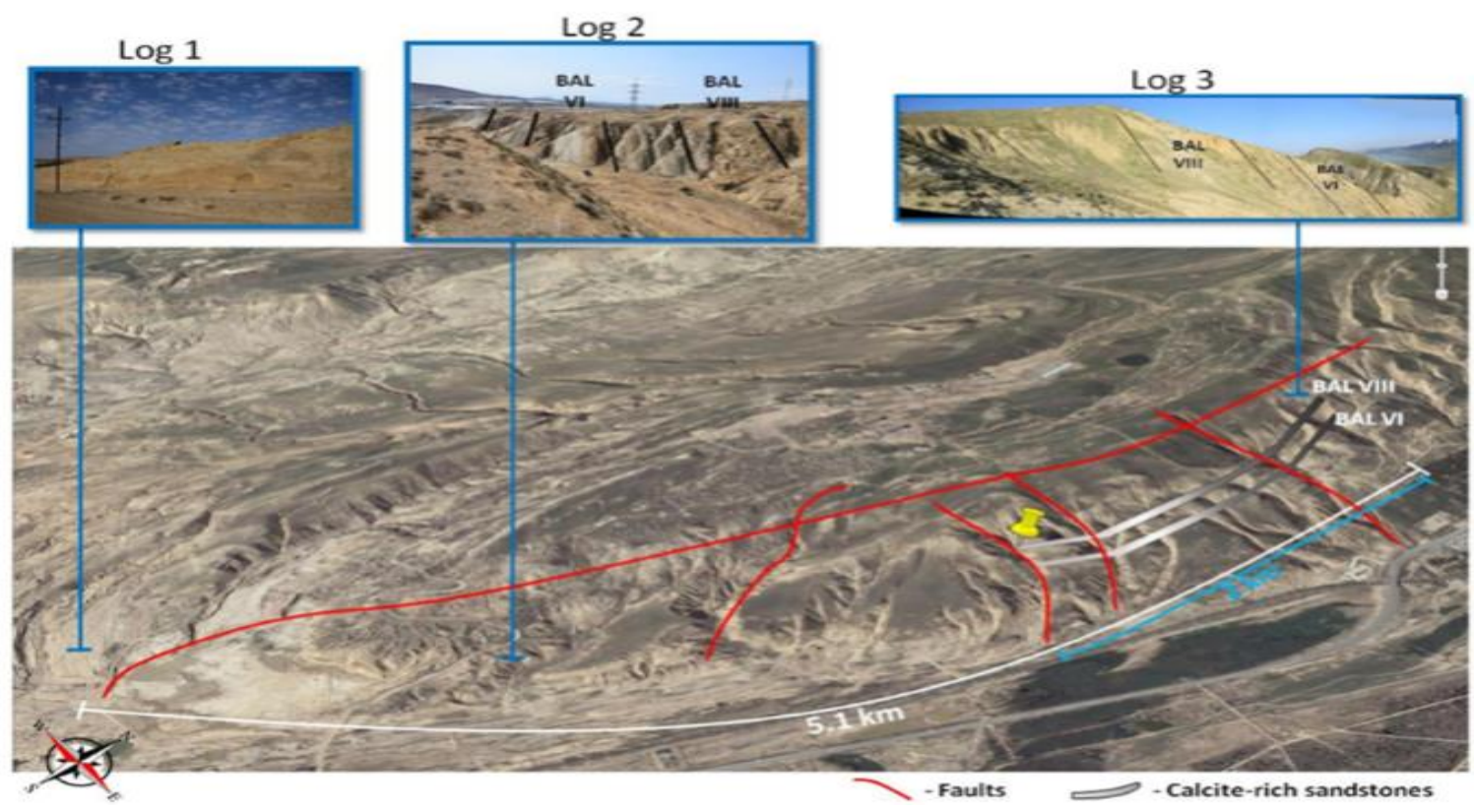

Figure 3. Outcrop of the Yasamal anticline, showing locations of logs (dark blue), faults (red) and distribution of calcite-rich sandstone layers (light-blue) in the Balakhany VI and the Balakhany VIII horizons of the Productive Series.

Study of the depositional environment of the Yasamal Valley during the Lower Pliocene (mainly Balakhany time) with relevance to deformation bands is important as changes in the depositional environment can result in variations in mineralogical composition and petrography of rocks, which
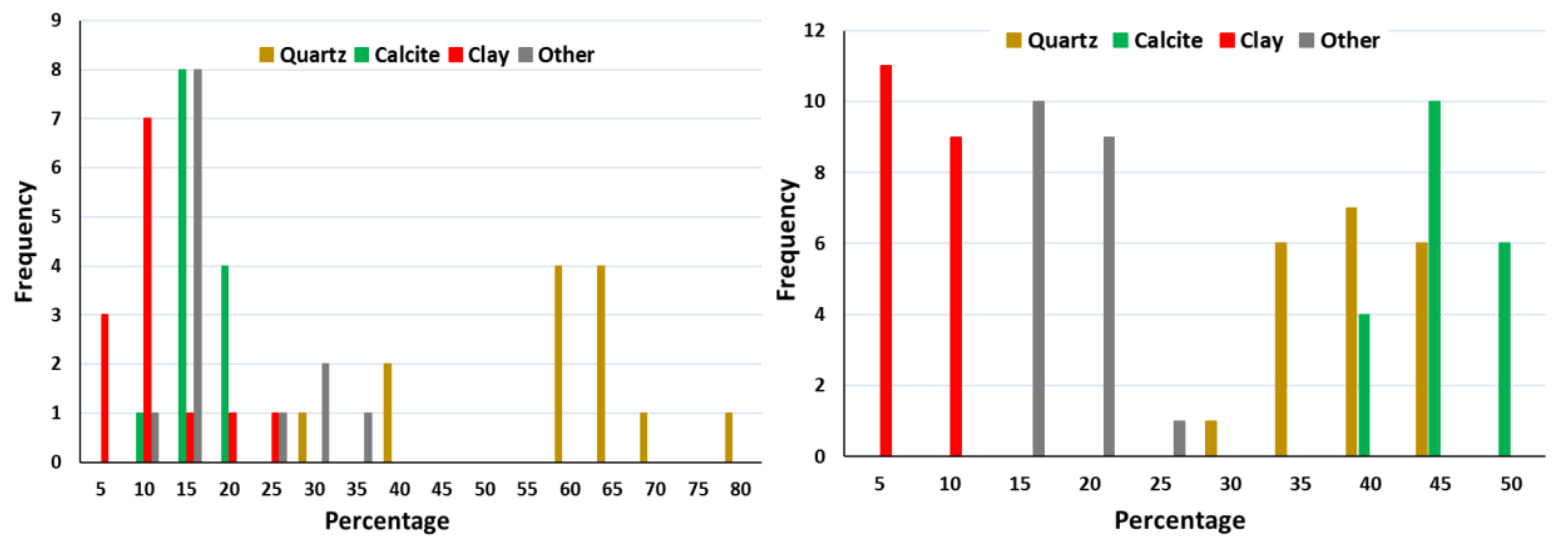

Figure 4. XRD-based distribution of minerals in the unconsolidated, relatively clean (left graph) and consolidated, calcite-rich (right graph) sandstones.

cause different mechanisms and intensity of deformation bands formation. Outcrop observations reveal two well exposed sandstone subunits: the thicker and coarser-grained sandstone outcrops of Balakhany VIII, and the thinner-bedded and finer-grained sandstone outcrops of Balakhany VI of the Productive series. These settings are interpreted as deposition during periods of increased fluvial- 
deltaic discharge and sediment supply. They mainly consist of amalgamated and braided fluvial sheet sandstones. These sandstones can be classified into two main types: 1) unconsolidated, relatively clean and 2) consolidated, calcite-rich. While the first type is observed across the entire structure, calcite-rich sandstones are locally distributed across the east limb, extending from its northern end of the structure (Fig.3). The latter are also more abundant in deformation bands, displaying complex patterns. XRD data show that these facies have a sharp contrast in mineralogical composition. While the percentage of calcite in unconsolidated sandstones varies between $10 \% 20 \%$, in calcite-rich sandstones it reaches 40-50\%. The unconsolidated sandstone layer without any deformation bands show $21.3 \%$ of total clay amount, composed of montmorillonite (10.7\%), illite (5.2\%) and kaolinite $(5.4 \%)$. This outcome is in a good agreement with estimated $\mathrm{V}_{\text {shale }}$ value of $18 \%$.

\section{Conclusions}

Characterization of sandstones in deformed areas is complicated by several factors that either counteract or enhance each other. Integration of field and laboratory results reveal appropriate model for prediction of deformation bands as a function of shale volume for Balakhany (Productive Series) sandstones. Threshold values set for unconsolidated and calcite-rich sandstones are among valuable inputs for prediction of deformation bands. Field observations suggest that ductility caused by high shale volumes make deformation band occurrence less dependent on formation dip angle. Furthermore, weak correlations between dip angle and number of deformation bands do not imply irrelevance of this parameter. Similar analysis involving deformation band count versus dip gradient might yield better results formation.

\section{References}

Allen, M. B., S. J. Vincent, G. I. Alsop, A. Ismail-zadeh, and R. Flecker. [2003] Late Cenozoic deformation in the South Caspian region: Effects of a rigid basement block within a collision zone: Tectonophysics, V. 366, p. 223-239.

Alizadeh, A.A., Akhmedov, G.A., Akhmedov, A.M., Aliyev, A.K., Zeynalov, M.M. [1966] Geology of oil and gas fields of Azerbaijan. Nedra, Moscow, pp.283-288. (in Russian)

Jones, R. W., Simmons, M. D. [1996] A review of the stratigraphy of Eastern Paratethys (Oligocene Holocene): Bulletin of the Natural History Museum London (Geology), V. 52, p. 25-49.

Gurevich, A., E., Chilingar, G., V. [1995] Abnormal pressures in Azerbaijan: A brief critical review and recommendations: Journal of Petroleum Science and Engineering, V. 13, no. 2, p. 125-135.

Reynolds, A. D., Simmons, M. D., Bowman, M. B. J., Henton, J., Brayshaw, A. C., Ali-Zadeh, A. A., Guliyev, I. S., Suleymanova, S. F., Ateava, E. Z., Mamedova, D. N., Koshkarly, R. O. [1998] Implication of outcrop geology for reservoirs in the Neogene, Apsheron Peninsula, Azerbaijan. AAPG Bulletin v. 82, p. 25-49.

Rotevatn, A., Sande, T.H., Keilegavlen. E., Kolyukhin, D., and Fossen, H. [2013] Deformation bands and their impact on fluid flow in sandstone reservoirs: the role of natural thickness variations. Geofluids V.13, pp.359-371

Tang, L.\&Cui, M. [2012] Structural deformation and fluid flow from East Sichuan to the northwestern periphery of the Xuefeng Uplift, China. Petroleum Science, Volume 9, Issue 4, pp 429-435

Zuluaga, L.F., Rotevatn, A. [2012] Structural reservoir heterogeneity induced by forced folding in sandstone reservoirs: the San Rafael Reef Monocline, Utah, USA. The Geological Society (Petroleum Group/Tectonic Studies Group Conference), London, 28-30 November. 